$\angle$ Research Square

Preprints are preliminary reports that have not undergone peer review.

They should not be considered conclusive, used to inform clinical practice,

or referenced by the media as validated information.

\title{
Did the animal move? A cross-wavelet approach to geolocation data reveals year-round whereabouts of a resident seabird.
}

Amédée Roy ( $\square$ amedee.roy@ird.fr)

Institut De Recherche Pour Le Developpement https://orcid.org/0000-0003-3047-1463

Karine Delord

Centre d'Etudes Biologiques de Chize

Guilherme Tavares Nunes

Universidade Federal do Rio Grande do Sul

Christophe Barbraud

Centre d'Etudes Biologiques de Chize

Leandro Bugoni

Universidade Federal do Rio Grande

Sophie Bertrand

Institut De Recherche Pour Le Developpement

\section{Research}

Keywords: activity pattern, breeding constraints, GLS, masked boobies, saltwater immersion, sexual dimorphism, Sula dactylatra

Posted Date: December 2nd, 2020

DOI: https://doi.org/10.21203/rs.3.rs-118834/v1

License: (9) This work is licensed under a Creative Commons Attribution 4.0 International License.

Read Full License 


\title{
Did the animal move? A cross-wavelet approach to geolocation data reveals year-round whereabouts of a resident seabird
}

\author{
Amédée Roy ${ }^{1 *}$, Karine Delord ${ }^{2}$, Guilherme T. Nunes ${ }^{3}$, Christophe Barbraud ${ }^{2}$, Leandro Bugoni ${ }^{4}$ and \\ Sophie Bertrand ${ }^{1,5}$
}

\footnotetext{
${ }^{*}$ Correspondence:

amedee.roy@ird.fr

1 Institut de Recherche pour le

Développement (IRD), UMR248 MARBEC

(IRD/CNRS/IFREMER/UM),

Avenue Jean Monnet, 34200,

Sète, France

Full list of author information is

available at the end of the article
}

\begin{abstract}
Background: Considerable progress in our understanding of long-distance migration has been achieved thanks to the use of small lightweight geolocator devices. Such global location sensors (GLS) are particularly suitable for studying non-breeding movement and behaviour due to their small size and low energy consumption allowing multiyear deployment. Errors of geolocation are however important, difficult to estimate, have a complex structure leading to poor precision and accuracy. Therefore, understanding movement ecology of short-distance migrants or resident birds during extensive time periods remains challenging. We aimed at elucidating the sex-specific marine space uses of a resident tropical seabird, the masked booby (Sula dactylatra) over the full annual life cycle, including the breeding and non-breeding periods.
\end{abstract}

Methods: A total of $34 \mathrm{GLS}$ were deployed on male and female masked boobies at the Fernando de Noronha archipelago (Brazil), and 31 of them were recovered and provided year-round data. Error range of geographical positions and habitat use of masked boobies were estimated from light-derived positions and temperature data. Synchronicity between movement and saltwater immersion data was investigated through a wavelet analysis.

Results: Masked boobies showed a resident behaviour over their entire annual cycle. We inferred from the wavelet analysis that birds traveled way and back from the colony on consecutive trips of short length $(\approx 2-4$ days $)$ and short range $(\approx 100-300 \mathrm{~km})$ at the east of the colony. Trip duration and range depended on the sex of the individual and on the time of the year. Females had farther ranges than males during the pre-breeding period. Trip duration increased gradually from the end of the breeding period to the post-breeding period, probably due to the release of the central-place breeding constraints.

Conclusions: Despite inherent limits of light-based geolocation, synchronicity analysis of geolocation data revealed year round whereabouts of a resident tropical seabird and sex-specific movement behaviour. Such an approach based on the estimation of synchronicity between light-based coordinates data and any other external data (behavioural or environmental) could be used more broadly to investigate resident or short-migrants animal movement based on GLS data.

Keywords: activity pattern; breeding constraints; GLS; masked boobies; saltwater immersion; sexual dimorphism; Sula dactylatra 


\section{Background}

Movement is a core feature of animal life cycle. At the individual level, animals move to feed, find mates, avoid risks such as predation or adverse climatic conditions, or to locate breeding areas, within the range of their motion and navigation abilities [1,2]. Birds in particular have not only a great mobility and control over their movement but also great orientation and navigation skills. Many birds are therefore able to travel quickly over long distances, to occupy distant areas at different seasons, returning repeatedly to the same localities from year to year. In opposition to these migratory populations, others can be referred as resident (or sedentary). A resident bird can be defined as one whose distribution and center of gravity remain more or less the same all year round, and from year to year [3].

Residency behaviour (i.e. no significant differences in distribution between breeding and non-breeding periods) might be explained by a reliable supply of food available locally all year, and/or if there are territorial advantages to regular year-round visits to their breeding site [3]. It therefore might be related to an energy-saving strategy, where birds avoid metabolic costs associated with migration, but rather invest energy in remaining in seasonally less favorable habitats [4]. Migration may have evolutionary consequences at the species level, as it increases the probability of encountering individuals from other populations and, consequently, of gene flow. Therefore, being resident can have important consequences on gene flow disruption between populations and on population genetic structures [5]. Residency behaviour is thus of great interest for future investigations into the topic of migration [6].

Resident seabirds are relatively rare in temperate and polar ecosystems, with a few exceptions [6]. Seabirds are constrained to breed on land, and most of them forage near breeding sites when incubating and provisioning offspring. After the breeding season, they are free to migrate to more favorable foraging habitats and to leave their breeding site over long periods. Numerous studies have thus demonstrated that seabirds exhibit seasonal, long-distance movements, particularly seabirds breeding in temperate or polar regions $[7,8]$. In the tropics, where seasonality is generally less pronounced [9], food resources have less seasonal variation than in temperate and polar regions [10], what partly explains why most tropical seabirds do not perform migrations to the same extent as seabirds breeding in temperate regions do [11]. Most studies on the movement of tropical seabirds are limited to breeding movement patterns, and to the analysis of foraging behaviour [12, 13, 14, 15]. Yet, there is definitely a need for studies on year-round movements in tropical seabirds as little is known on their post-breeding movements and activity patterns. In addition these species represent half the number of all seabirds [16] and tropical ecosystems are facing mounting threats [17]. Few studies have attempted to elucidate tropical seabirds' movement patterns outside the breeding period [18, 19]. To our knowledge none of them have explored the non-breeding behaviour of tropical sulids, even if they are usually considered as resident birds [20, 21].

Indeed, it is very challenging to accurately track year-round resident seabirds. Despite technical advances in the miniaturization and autonomy of devices, great challenges remain to deploy precise and accurate sensors over long period such as GPS loggers [22, 23] Light-level geolocation thus remains a preferred option for studying non-breeding seabird spatial behaviour perennially [24, 25] Light-level 
data loggers or geolocators (global location sensor, GLS), are small enough to be attached (i.e. leg-mounted on a ring), energy-efficient enough to be deployed for up to several years, and with reduced costs. However, errors of geolocation are important, difficult to estimate, have a complex structure leading to poor precision and accuracy [26, 27, 28]. For such reason, GLS and associated analytical methods are considered relevant mostly for elucidating migratory movements of wide-ranging animals, including terrestrial passerines (e.g. [29, 30]), and seabirds (e.g. [31, 32]). The analysis of geolocation data derived from a resident species (or from any nonmigratory behaviour) is indeed challenging: when animal movements are in the order of magnitude of geolocation errors (e.g. $65+/-54 \mathrm{~km}$ in longitude and 358 $+/-499$ in latitude, as estimated in our study Figure 1), the stumbling block remains in detecting animal movements and in distinguishing movements from geolocation error.

In this study, we used light-level geolocators to understand year-round at-sea movements of a tropical resident seabird: the masked booby (Sula dactylatra). Masked booby is a pan-tropical seabird found in every ocean on or off nearly every coast except the eastern Atlantic, northern Indian Ocean and the central-eastern Pacific. This species has been the subject of a relatively large number of movementbased studies (see [15]). Yet, to our knowledge it has been restricted to foraging trips during the breeding period only. Thus, masked boobies' movements during the nonbreeding period remain unclear. In [33], the authors suggested that young masked boobies may disperse extensively, but that adults are usually present year-round in the vicinity of the colony, while in [34] they suggested that adults may disperse widely (thousands of $\mathrm{km}$ from the colony) after the breeding season, following vagrant movement patterns and resting on rocks and islands. They also underlined that masked boobies maintain a territorial behaviour, post-breeders returning eventually back to colony intermittently [34]. Apart from the uncertainties related to masked boobies post-breeding whereabouts, other questions remains, particularly concerning their reversed sexual dimorphism (RSD, females are heavier and larger than males). Several studies have expected a sex-related differences in the foraging strategies of masked boobies, assuming that the challenges related to foraging in tropical ecosystems characterized by low productivity presumably exert strong selection pressure for the body size differences in tropical seabird species [13, 35]). However, if some studies suggested a higher foraging effort by females [36], most of them did not demonstrate differences between sexes in foraging trips [37, 38, 39].

Here we therefore had two main objectives. First, to elucidate the post-breeding movements of masked boobies and sex-specific non-breeding behaviours. Second, to demonstrate the relevance of wavelet analysis as a visualization tool for GLS data derived from short-migrants or resident species. The guiding idea of this approach is to explore relationships between external behavioural and movement data through a cross-wavelet analysis in order to detect when masked boobies leave their colony. The overarching hypothesis would be that if there is significant synchronicity between saltwater immersion time-series and light-based position estimations this reveals with higher confidence that the position deviation to the colony is related to real movement rather than geolocation error. Therefore, such analysis would allow us to identify when seabirds leave their colony, for how long and approximately how far, and to identify activity patterns, despite the GLSs' obvious lack of accuracy. 


\section{Methods}

\section{Study site}

Fernando de Noronha (hereafter FdN, $03^{\circ} 50^{\prime} \mathrm{S}, 32^{\circ} 30^{\prime} \mathrm{W}$ ) is an offshore archipelago (21 islands and islets, $18.2 \mathrm{~km}^{2}$ ) lying at $360 \mathrm{~km}$ east from the mainland city of Natal, Brazil. FdN is a clear priority for biodiversity conservation at the Brazilian federal state level (through the Ministry of Environment, ICMBIO) and scientific data are critical for improving the design of conservation policies. In particular, ICMBIO needs to know if Brazil carries the entire conservation responsibility of the species attending FdN archipelago (in case they are resident) or if international actions need to be taken at the tropical Atlantic Ocean scale (in case they disperse over wider areas). This archipelago hosts the highest diversity of seabirds in Brazil, with eleven species reported to breed there [40]. In order to elucidate the yearround whereabouts of masked boobies breeding on the archipelago, fieldwork was conducted on one of the secondary island, Meio island, which hosts one of the main masked booby breeding colony with $\approx 388$ active nests (i.e. with eggs or chicks) censused in April 2018.

\section{GLS deployment}

Breeding adults raising two to seven weeks old chicks were caught on 4-6 May 2017 and fitted with a leg-mounted GLS. In total, 34 individuals were caught (16 females and 18 males) and two types of GLS were deployed ( $\mathrm{n}=20$ MK3006 and $\mathrm{n}=14$ MK3005 models from Biotrack Ltd., Wareham, UK). GLS weighted $2.5 \mathrm{~g}$ and were fixed to a plastic ring $(2 \mathrm{~g})$ with cable ties, the entire equipment corresponding to $0.3 \%$ of the body mass.

Loggers recorded daylight level intensity every $60 \mathrm{~s}$ and the maximum light intensity for each $10 \mathrm{~min}$ for MK3006 and each $5 \mathrm{~min}$ for MK3005. In addition to light, GLS loggers recorded saltwater immersion (i.e. activity data) and sea surface temperature data.

\section{GLS data analysis}

Light-based geolocation

Twilight times (i.e. sunrise and sunset) were determined using an arbitrary light intensity threshold. A good choice for light threshold is often the lowest value that is consistently above any noise in the nighttime light levels, slightly above complete darkness [41]. It was performed through the existing $\mathrm{R}$ library TwGeos [42].

Calibration step is the most important step in any geolocator analysis and has been executed very carefully following [43] recommendations. Each sensor was calibrated during deployment period for a so-called "in-habitat calibration". As birds fitted with GLS were breeding young chicks, and relying on our knowledge of the phenology of masked boobies based on in situ observations, we assumed that birds stayed at their breeding place at least from 2017-05-10 to 2017-06-15.

For the estimation of geographic locations one need to establish a sun elevation angle (or zenith angle) that would correspond to the fixed light intensity threshold. This angle is known to be specific to each individual tags. Therefore, one angle was determined per tag so that it minimized the error in latitude during the calibration period (known as the Hill-Ekstrom calibration). These solar angles were then used to derive estimated birds' geographic positions over the whole deployment. This was performed through the existing R library SGAT [44]. 


\section{Saltwater immersion and temperature data}

Geolocation by light using the threshold method provides two positions per day: more precisely one position from two consecutive twilight. Therefore, mean temperature and time spent in wet environment were computed between every two twilights for each individual sensor in order to get one value of behavioural data per position.

The OSTIA global sea surface temperature reprocessed product provided by the Copernicus Marine Service (product identifier SST_GLO_SST _L4_REP_OBSERVATIONS_010_001) was used to compute the deviation between mean temperature recorded by the tags and the sea surface temperature from satellite observations.

\section{Maps of error and habitat range}

Based on all twilight times deviation estimated for each individual during the calibration period a gamma distribution was fitted in order to define a global twilight error structure (Figure 1). Temperature error structure was defined as a uniform distribution based on the theoretical sensor accuracy given by the archival tag provider (Biotrack Ltd., Wareham, UK). Then, maps of error were estimated by simulating twilight times that could have been recorded by a geolocator supposed at the colony during the whole deployment and based on the twilight error structure estimated during the calibration. Positions were derived with a threshold method, and density was estimated with a Kernel Density Estimation (KDE). The likelihood of each position was estimated by computing the deviation between the OSTIA-derived temperature data at the simulated location and at the breeding place. Deviations within the error range $\left( \pm 0.5^{\circ} \mathrm{C}\right)$ were associated with a likelihood of 1 , else 0 (Figure 2).

Maps of habitat were estimated with the same methodology but using observed data from all geolocator rather than simulated data. A KDE was used given all observed coordinates. The likelihood of each position was estimated by computing the deviation between the OSTIA-derived temperature data at the estimated location and the observed temperature by the sensor (Figure 2).

Cross-wavelet analysis

In order to elucidate the relationships between movement and activity time-series, a cross-wavelet analysis was performed, with the two distinct time-series of mean time in wet immersion, and longitude, since longitude is more accurately estimated than latitude $[45,46]$.

Wavelet analysis basically provides appropriate tools for comparing the frequency contents of these two time-series, drawing conclusions about the series' synchronicity at certain periods and across certain ranges of time. Wavelet analyses have been widely used in ecology (e.g. $[47,48,49,50]$ ) since this method is highly appropriate to analyze periodic patterns in biological time series that are often noisy, non-linear and non-stationary [51].

Wavelet analysis aims at achieving a local scale decomposition of a signal $y(t)$ through the computation of the wavelet coefficient:

$$
W_{y}(a, \tau)=\int_{-\infty}^{+\infty} y(t) \Psi_{a, \tau}(t)
$$


where $\Psi_{a, \tau}$ is the mother wavelet in its conjugate form, $\tau$ represents time, and $a$ is the scale of the wavelet (Figure 3 ). The wavelet coefficient represents the contribution of a scale $a$ (i.e. the time periods on vertical axis in Figures 3 and 4 ) in the observed signal at time $\tau$ (i.e. the absolute time on horizontal axis in Figures 3 and 4). In other words, the more the signal $y(t)$ at time has a pattern with the same period as $\Psi_{a, \tau}$, the higher is $W_{y}(a, \tau)$. In practice, the Morlet wavelet is the most widely used mother wave, and is known for performing a good trade-off between temporal and scale resolutions [52].

The cross-wavelet transform of two time series $x(t)$ and $y(t)$, with respective wavelet transforms $W_{x}$ and $W_{y}$ is finally defined by:

$$
W_{x, y}(a, \tau)=\frac{1}{\tau} \cdot W_{x}(a, \tau) \cdot W_{y}(a, \tau)
$$

As recommended by $[53,54]$, the evaluation of the statistical significance of these power cross-wavelet coefficients is critical for interpreting them correctly. The significance test involves a null hypothesis of "no joint periodicity", and performs simulations of random time series in order to estimate the cross-wavelet coefficients range under the null hypothesis. By fixing a level of significance it therefore clusters the data depending on the observation (or not) at each moment of the deployment of statistically significant correlation between the two observed time-series. Thus, as a null hypothesis we simulated by random sampling longitude and mean time in saltwater immersion. Since masked boobies spend quite a lot of time in dry environment during the day (specifically during the breeding period), care was taken to sample separately day and night activity data. Analysis were conducted with the help of the WaveletComp R library [55].

\section{Results}

The geolocation-immersion loggers were recovered during the following breeding season during the second half of April 2018 (31 loggers recovered, i.e. 91\% recovery rate), and the light-based geolocation approach revealed that no masked booby had shown any migratory or wide-range movement. The deviation of twilight times during the calibration period were never above $30 \mathrm{~min}$, and distributions had a non-symmetric shape as developed in [27], with maximum-likelihood fitted gamma distribution of scale 2.66 and rate 0.32 (Figure 1 ). The deviation of temperature was mainly in the range of $-0.5^{\circ} \mathrm{C}$ to $+0.5^{\circ} \mathrm{C}$ which is the theoretical sensor accuracy (Biotrack Ltd., Wareham, UK). These deviations extended to the whole deployment $(\approx 350$ days) were only slightly different. Quantitatively, the associated error range estimation and habitat were very similar with a Bhattacharyya coefficient of 0.97 and 0.95 when comparing estimated maps respectively with and without likelihoodweighted coordinates (Figure 2). Yet, highest deviations were observed for days when the bird spent more than $75 \%$ in wet environments. For instance, negative twilight deviation was computed (up to -10 minutes) in such wet environments, implying an associated longitude deviation in the estimated positions of $\approx 150 \mathrm{~km}$ to the east of the breeding colony (Figures $1 \& 2$ ).

The cross-wavelet analysis revealed local significant joint-periodicities (i.e. synchrony) between longitude and saltwater immersion time-series for every individual 
(p-value $<0.01)$. This synchronicity appeared for different couple of specific periods and times and they are discernable in matrixes of cross-wavelet power coefficients. Figure 3 illustrates how to interpret such matrixes. In particular, it focuses on extracts of the two studied time-series measured by one tag, with a period with significant synchrony (panel b). It shows that during approximately 20 days, longitude and saltwater immersion synchronized with periodicity of around 96h. It consists roughly in alternative dry periods of $48 \mathrm{~h}$ followed by periods of $48 \mathrm{~h}$ spent in wet environments shifted a few degrees eastward. The white arrows pointing to the right indicate that the two series are in phase at the respective period [55]. In other words, it means that eastward movement (longitude increasing) corresponds to an increase of activity and to substantial time spent in wet environments, which can be due to resting at the ocean surface, and equally westward movement (longitude decreasing) corresponds to a decrease of activity and to substantial time spent in dry environments which can be due to staying at the colony. This indicates that during this significant joint period the individual might have traveled way and back to its colony, and have stayed in the eastern part of FdN Archipelago for about 2 days in wet environments. In opposition, during periods without joint periodicity we have no accurate information on bird movement.

The average matrixes of cross-wavelet power coefficient for all individuals show global patterns of joint synchronicity, and a strong relationship with the phenology of masked boobies (Figure 4). Periods with almost no significant periodicity occurred mostly between March and July which correspond to the first stage of the breeding period (laying to hatching). In particular, during hatching (mid-May to mid-June) almost no birds have shown significant synchronicity. In contrast, from July to March, which corresponds to the end of the breeding season and until the end of the non-breeding season the following reproductive period, significant jointperiodicity can be observed for both females and males. They occurred mainly for periods of 2 to 8 days, with a modal period that increases from 2 in July to 5 days in November. We can also observe specific period where all birds seem to stop showing joint-periodicity such as in the end of September or in mid-December. Differences by sex appeared when breeding is over, i.e. after fledging (Figure 4c'), with higher power coefficient, and with significant higher eastwards deviations from the colony of geographical coordinates associated to days with highly wet environments $>75 \%$ for females (Welch Two Sample t-test: p-value $<0.001$ ).

\section{Discussion}

\section{GLS data and resident behaviour}

Data from our 31 tracking tags showed that Masked Boobies from FdN archipelago were staying in the vicinity of their breeding site both during breeding and nonbreeding season. The cross-wavelet analysis revealed joint-periodicity between longitude and saltwater immersion time-series, with longitude increases related to substantial time spent in wet environments for periods of about 4 to 8 days. We inferred from this pattern that the tagged birds traveled way and back from the colony on consecutive trips of short length $(\approx 2-4$ days $)$ and short range $(\approx 100-300 \mathrm{~km})$ at the east of the colony, with length and range depending on the sex of the individuals and on the time of the year. 
GLS data have been only rarely used to demonstrate resident behaviour [6]. Existing studies have dealt with staging behaviour and most of them have estimated habitat zones by applying kernel density estimation (KDE) on a scatter of lightderived positions $[56,57]$. They have tempted to distinguish travelling from resting periods by fixing empirical thresholds on distance to the colony [58] or on change in longitude [59]. Nevertheless, all insisted to be cautious when interpreting such data. Due to inherent limits of light-based geolocation accuracy, habitat zone estimation derived from GLS data often leads to a scatter of coordinates extended in latitude. In this study, we estimated the error range, and we demonstrated its similarity with the estimated habitat of FdN's masked boobies. This suggests that such habitat zones reflect mostly errors and are not particularly ecologically relevant apart from the fact that they indicate residential behaviour. One could argue that it would be impossible to detect wide range movements in case seabirds would have changed of breeding location or simply skipped the breeding season. Indeed, because birds with archival tags needed to be recaptured, we only recovered tags that have been deployed on birds that bred at the same place for two consecutive years. However, previous observations [60], as well as our own with recovery rate around $90 \%$ suggests that such behaviour would be rather rare, especially since the remaining fraction cannot be disentangled from natural mortality estimated at $8.6 \%$ by [61].

Our study reveals joint-periodicity between longitude and saltwater immersion time-series, with longitude increases related to substantial time spent in wet environments for periods of about 4 to 8 days. Such results do not explicitly demonstrate that birds actually performed short trips to the east of FdN. Nevertheless they reveal a relationship between activity patterns and geographic location estimations. This pattern may result from real eastward movements or there might be some bias in the measure of light-level intensity when masked boobies are in wet environments causing a deviation to the east. This second hypothesis was however unlikely. Indeed, shading due to immersion could explain a positive twilight deviation, but it is unlikely that it could explain the negative twilight deviation observed in Figure 1, since negative twilight error are theoretically impossible with GLS data, especially in environments with no artificial lights. It would also be difficult to explain the highest temperature deviation that we observed in Figure 1, assuming satellite data were accurate. Finally, GPS tracking of masked boobies in the same colony during the breeding season conducted in every April between 2017 and 2019 revealed that masked boobies from FdN forage almost exclusively at the east of FdN, and that they eventually spent one night eastward of their breeding locations ( 8 out of 130 recorded trips, S. Bertrand, unpublished data). Such nights at sea might be observable in our datasets ( $\approx 1$ or 2 birds among 31 tracked birds), and Figure 4 indicates that in April at least one male showed a joint periodicity of period $48 \mathrm{~h}$, which corresponds to $24 \mathrm{~h}$ spent in a wet environment at the east of the colony. Based on our analysis, we are thus confident that masked boobies travelled way and back to the colony during the non-breeding season and beginning of breeding season, and that the eastward deviation consisted in real movements of about $150 \mathrm{~km}$ eastward to FdN. 
Masked boobies' year-round residency

Breeding masked boobies from Noronha mainly feed on flying fishes (unpublished data, consistent with other sites reported in [34]). Despite the archipelago being surrounded by oligotrophic waters, the residence of masked boobies would suggest that flying fish are present in similar abundances throughout the year. Moreover, the fact that seabirds forage year-round eastward of the archipelago might be related to the presence of twice more productive areas at the north-east of FdN due to the island effect of São Pedro São Paul offshore archipelago, which is known to trigger a local enrichment in the surrounding waters through an upwelling island effect [62]. The intermittent way back to the colony is also in line with the territorial behaviour of Masked Boobies [34]. Masked Boobies are known to inspect breeding areas by aerial reconnaissance and on foot, and to defend nesting territories through ritualized in-flighting signals of site-ownership, vocalizations, wing-flailing, or jabbing.

Most previous studies on seabirds at FdN relied on colony-based sightings $[63,40,64]$ and stable isotope analyses for trophic ecology $[65,66]$. These authors underlined the need for going further in the study of the ecology of seabirds at FdN, especially on their movement and the definition of their habitat, so as to improve conservation strategies. This work provides a first answer on masked boobies yearround behaviour, inferring their non-migratory behaviour and their habitat zone. In particular, masked boobies stay within the Brazilian Exclusive Economic Zone throughout the year, which can bring valuable information for developing relevant conservation strategies such as designing marine protected area.

\section{Sex-specific activity patterns}

If some uncertainties remain on the exact locations and habitat zone of masked boobies, our study brings new insights on temporal variation of their space use. In particular, we show a strong relationship between the duration of trips outside FdN and breeding constraints. Laying, incubating and hatching periods were associated with no joint periodicity, suggesting that the range and duration of foraging trips during these periods are below the error threshold of the signal provided by light and activity. These breeding stages are characterized by substantial thermical and energetical constraints linked to reproduction since adults need to incubate or to brood their chick and to feed them. They mostly spend time in defending the nest site or their chick and foraging at sea. Therefore, they are not expected to spend time resting at the sea surface for long periods during breeding (e.g. within the timeframe of two locations per day derived from GLS). Even if they forage far from their colony they have to come back frequently, and are likely to be observed at FdN. When chicks are older and can survive without the protection of their parents (i.e. rearing to fledging), the release of the thermical constraints was illustrated by joint-periodicity with gradually increasing periods. Trips outside the breeding period lasted from 1 day in July-August to 3 days in October-November.

Interestingly, when there was no constraint related to reproduction (i.e. no strict obligation to return to the nest), male and female showed slight differences in crosswavelet power, particularly the few months prior breeding. During this specific period (January to March), the cross-wavelet revealed higher power coefficients for 
females, which can be explained by longer trips. The median longitudinal deviation of coordinates of days spent in wet environments ( $>75 \%)$ from January 2018 was significantly higher for females $(\approx 200 \mathrm{~km})$ than for males $(\approx 150 \mathrm{~km})$. Our results confirm the fact that for this species, attendance at site prior to egg-laying is larger for male than for female [34]. Males are territorial and work at conquering a nest place at that period, from where they perform sexual 'advertising' on the ground by sky-pointing. By going further eastward, females may go closer to São Pedro São Paul offshore archipelago and reach more productive area [62], at a period where they need to accumulate energy for the ovogenesis. This sexual segregation in space use in the pre-breeding period (which is not observed during the breeding period) provides a new light on RSD of masked boobies. One of the functions proposed for RSD is niche segregation, especially to avoid intersexual competition and optimize the use of resources [67]. Where many studies have failed to demonstrate differences in foraging behaviours of masked boobies in order to explain masked boobies' reversed sexual dimorphism, our own study provide relevant sex-specific activity patterns in the pre-laying period.

Wavelet analysis of geolocation data

When dealing with GLS data deployed on resident or other non-migratory animals, the question might not be "where is the animal?" but rather "did the animal move?". In this situation, we might need external data in order to determine movement based on a relevant correlation. This is the case in our study, where we aimed at determining masked boobies' movements by studying the relationships between saltwater immersion and longitude. Our analytical framework could easily be used in order to investigate the space-uses of other resident seabirds, such as other sulids or cormorants. But, it is also the case in other studies such as in [68], where the authors compared warblers' positions derived from light-level intensities with precipitable water in the atmosphere as a proxy of cloud covering in order to show that high deviations in position might be due to shading due to weather. We do think that wavelet analysis can provide a powerful solution in both cases. Indeed, it is a great tool for studying the sequentiality of noisy time-series such as light-derived positions, and for exploring significant synchronicity between such time-series coupled with any other relevant external data (weather data, behavioural data, etc...). Moreover, it is really straightforward to use with tools such as WaveletComp R package [55].

\section{Conclusion}

To conclude, despite the inaccuracy of GLS geolocation, our study shows it is appropriate for revealing year-round whereabouts of a resident tropical seabird over long periods, such as during the non-breeding season. Indeed, thanks to time-series with higher precision and reliability recorded by GLS such as temperature and saltwater immersion we can extract more out of GLS data, particularly by elucidating activity patterns, and saltwater immersion bouts. We brought new insights on masked boobies movement patterns related to breeding constraints, and we revealed prebreeding sex-specific movements that had not been observed to date. Finally, we think that wavelet analysis is a relevant way to extract more out of GLS data further 
broadly, to provide strong demonstration of animal movement or residency, and to support ecologists in their effort to avoid as much as possible over-interpretation of GLS data.

\title{
Appendix
}

\author{
Acknowledgements \\ Fieldwork activities received the administrative and logistical support from the Fernando de Noronha \\ administration, the Instituto Chico Mendes de Conservação da Biodiversidade (ICMBio, Brazil), the military \\ firemen from Fernando de Noronha and the TAMAR Project. We also want to express grateful thanks to \\ anonymous reviewers and to colleagues from IFREMER and IRD for having helped us significantly on the \\ manuscript.
}

\section{Funding}

This work is a contribution to the TRIATLAS project (funding by the European Union's Horizon 2020 research and innovation program - grant agreement No. 817578). This project has received funding from the Paddle Rise project - European Union's Horizon 2020 research and innovation program under Grant Agreement No 734271. This study was partially funded by IRD (Mixed International Laboratory Tapioca), CPER Celimer (France), Fundação O Boticário (Brazil), Brazilian National Research Council (CNPq, No. 422759/2016-3). L.B. is research fellow from CNPq (PQ 311409/2018-0).

Abbreviations

GLS, FdN, KDE

Availability of data and materials

Data will be added to Movebank. It is for the moment on our github page:

https://github.com/AmedeeRoy/WaveLightGLS.

Ethics approval and consent to participate

Not applicable.

Competing interests

The authors declare that they have no competing interests.

Consent for publication

Not applicable.

Authors' contributions

A.R., S.B. and K.D. conceived the ideas and A.R. performed the analysis; A.R., G.T.N., K.D., C.B., K.D. and S.B. have been on fieldworks for collecting the data; A.R. led the writing of the manuscript. All authors contributed critically to the drafts and gave final approval for publication.

\section{Authors' information}

Not applicable.

\section{Author details}

1 Institut de Recherche pour le Développement (IRD), UMR248 MARBEC (IRD/CNRS/IFREMER/UM), Avenue Jean Monnet, 34200, Sète, France. ${ }^{2}$ Centres d'Etudes Biologiques de Chizé, UMR7372 Centre National de la Recherche Scientifique, 79360, Villiers en Bois, France. ${ }^{3}$ Centro de Estudos Costeiros, Limnológicos e Marinhos, Universidade Federal do Rio Grande do Sul (UFRGS), Campus Litoral Norte, Avenida Tramandaí, 976, 95625-000, Imbé, RS, Brazil. ${ }^{4}$ Biological Sciences Institute and Seabirds and Sea Turtles Laboratory, Universidade Federal do Rio Grande (FURG), Avenida Itália, km 8, Carreiros, 96203-900, Rio Grande, RS, Brazil. ${ }^{5}$ Departamento de Pesca e Aquicultura, Departamento de Biometria, Universidade Federal Rural de Pernambuco (UFRPE), Rua Dom Manuel de Medeiros, Dois Irmãos, 52171-900, Recife, PE, Brazil.

\section{References}

1. Bowler DE, Benton TG. Causes and consequences of animal dispersal strategies: relating individual behaviour to spatial dynamics. Biological Reviews. 2005;80:205-225.

2. Nathan R, Getz WM, Revilla E, Holyoak M, Kadmon R, Saltz D, et al. A movement ecology paradigm for unifying organismal movement research. Proceedings of the National Academy of Sciences. 2008;105:19052-19059.

3. Newton I. The migration ecology of birds. London: Academic Press; 2010.

4. Garthe S, Ludynia K, Hüppop O, Kubetzki U, Meraz JF, Furness RW. Energy budgets reveal equal benefits of varied migration strategies in northern gannets. Marine Biology. 2012;159:1907-1915.

5. Friesen VL, Burg TM, McCOY KD. Mechanisms of population differentiation in seabirds. Molecular Ecology. 2007;16:1765-1785.

6. Schacter CR, Jones IL. Confirmed year-round residence and land roosting of Whiskered Auklets ( Aethia pygmaea ) at Buldir Island, Alaska. The Auk. 2018 Jul;135:706-715.

7. Wilson RP, Culik BM, Kosiorek P, Adelung D. The over-winter movements of a chinstrap penguin (Pygoscelis antarctica). Polar Record. 1998;34:107-112.

8. Weimerskirch H, Wilson RP. Oceanic respite for wandering albatrosses. Nature. 2000;406:955-956. 
9. Longhurst AR, Pauly D. Ecology of tropical oceans. 574.52636 L6. San Diego: Academic Press; 1987.

10. Ashmole NP. Seabird ecology and the marine environment. Avian Biology. 1971;1:223-286.

11. Catry T, Ramos J, Le Corre M, Phillips R. Movements, at-sea distribution and behaviour of a tropical pelagic seabird: the wedge-tailed shearwater in the western Indian Ocean. Marine Ecology Progress Series. 2009;391:231-242.

12. Le Corre M, Jaeger A, Pinet $P$, Kappes MA, Weimerskirch $H$, Catry $T$, et al. Tracking seabirds to identify potential Marine Protected Areas in the tropical western Indian Ocean. Biological Conservation. 2012;156:83-93.

13. Lewis S, Schreiber EA, Daunt F, Schenk GA, Orr K, Adams A, et al. Sex-specific foraging beiiaviour in tropical boobies: does size matter? Ibis. 2005;p. 7.

14. Weimerskirch $\mathrm{H}$, Le Corre M, Bost C. Foraging strategy of masked boobies from the largest colony in the world: relationship to environmental conditions and fisheries. Marine Ecology Progress Series. 2008;362:291-302.

15. Wilkinson BP, Haynes-Sutton AM, Meggs L, Jodice PGR. High spatial fidelity among foraging trips of Masked Boobies from Pedro Cays, Jamaica. PLOS ONE. 2020;15:e0231654.

16. Schreiber EA, Burger J, editors. Biology of marine birds. Hoboken, USA: CRC press; 2001.

17. Reboredo Segovia AL, Romano D, Armsworth PR. Who studies where? Boosting tropical conservation research where it is most needed. Frontiers in Ecology and the Environment. 2020;18:159-166.

18. Jaeger A, Feare CJ, Summers RW, Lebarbenchon C, Larose CS, Le Corre M. Geolocation Reveals Year-Round at-Sea Distribution and Activity of a Superabundant Tropical Seabird, the Sooty Tern Onychoprion fuscatus. Frontiers in Marine Science. 2017;4:394.

19. Kohno H, Mizutani A, Yoda K, Yamamoto T. Movements and activity characteristics of the brown booby (Sula leucogaster) during the non-breeding period. Marine Ornithology. 2019;47:169-174.

20. Ballance LT, Pitman RL, Fiedler PC. Oceanographic influences on seabirds and cetaceans of the eastern tropical Pacific: A review. Progress in Oceanography. 2006;69:360-390.

21. Diamond AW. Feeding Strategies and Population Size in Tropical Seabirds. The American Naturalist. 1978;112:215-223.

22. Hussey NE, Kessel ST, Aarestrup K, Cooke SJ, Cowley PD, Fisk AT, et al. Aquatic animal telemetry: A panoramic window into the underwater world. Science. 2015;348:1255642-1255642.

23. Ropert-Coudert Y, Beaulieu M, Hanuise N, Kato A. Diving into the world of biologging. Endangered Species Research. 2009;10:21-27.

24. Wakefield E, Phillips R, Matthiopoulos J. Quantifying habitat use and preferences of pelagic seabirds using individual movement data: a review. Marine Ecology Progress Series. 2009;391:165-182.

25. Wilson R, Grémillet D, Syder J, Kierspel M, Garthe S, Weimerskirch H, et al. Remote-sensing systems and seabirds: their use, abuse and potential for measuring marine environmental variables. Marine Ecology Progress Series. 2002;228:241-261.

26. Ekstrom P. Error measures for template-fit geolocation based on light. Deep Sea Research Part II: Topical Studies in Oceanography. 2007;54:392-403.

27. Lisovski S, Hewson CM, Klaassen RHG, Korner-Nievergelt F, Kristensen MW, Hahn S. Geolocation by light: accuracy and precision affected by environmental factors. Methods in Ecology and Evolution. 2012;3:603-612.

28. Phillips R, Silk J, Croxall J, Afanasyev V, Briggs D. Accuracy of geolocation estimates for flying seabirds. Marine Ecology Progress Series. 2004;266:265-272.

29. Hobson KA, Kardynal KJ. Western Veeries use an eastern shortest-distance pathway: New insights to migration routes and phenology using light-level geolocators. The Auk. 2015;132:540-550.

30. Tøttrup AP, Klaassen RHG, Strandberg R, Thorup K, Kristensen MW, Jørgensen PS, et al. The annual cycle of a trans-equatorial Eurasian-African passerine migrant: different spatio-temporal strategies for autumn and spring migration. Proceedings of the Royal Society B: Biological Sciences. 2012;279:1008-1016.

31. Egevang C, Stenhouse IJ, Phillips RA, Petersen A, Fox JW, Silk JRD. Tracking of Arctic terns Sterna paradisaea reveals longest animal migration. Proceedings of the National Academy of Sciences. 2010;107:2078-2081.

32. González-Solís J, Croxall JP, Oro D, Ruiz X. Trans-equatorial migration and mixing in the wintering areas of a pelagic seabird. Frontiers in Ecology and the Environment. 2007;5:297-301.

33. Del Hoyo J, Elliott A, Sargatal J. HandBook of the birds of the world. vol. 1. Barcelona: Lynx Editions; 1992.

34. Nelson B. Pelicans, cormorants, and their relatives. Oxford University Press; 2005.

35. Weimerskirch H, Corre ML, Ropert-Coudert Y, Kato A, Marsac F. Sex-specific foraging behaviour in a seabird with reversed sexual dimorphism: the red-footed booby. Oecologia. 2006;146:681-691.

36. Weimerskirch H, Le Corre M, Gadenne H, Pinaud D, Kato A, Ropert-Coudert Y, et al. Relationship between reversed sexual dimorphism, breeding investment and foraging ecology in a pelagic seabird, the masked booby. Oecologia. 2009;161:637-649.

37. Poli CL, Harrison AL, Vallarino A, Gerard PD, Jodice PGR. Dynamic oceanography determines fine scale foraging behavior of Masked Boobies in the Gulf of Mexico. PLOS ONE. 2017;12:e0178318.

38. Sommerfeld J, Kato A, Ropert-Coudert Y, Garthe S, Hindell MA. Foraging Parameters Influencing the Detection and Interpretation of Area-Restricted Search Behaviour in Marine Predators: A Case Study with the Masked Booby. PLoS ONE. 2013;8:e63742.

39. Young H, Shaffer S, McCauley D, Foley D, Dirzo R, Block B. Resource partitioning by species but not sex in sympatric boobies in the central Pacific Ocean. Marine Ecology Progress Series. 2010;403:291-301.

40. Mancini PL, Serafini PP, Bugoni L. Breeding seabird populations in Brazilian oceanic islands: historical review, update and a call for census standardization. Ornithology Research. 2016;24:94-115.

41. Pollet IL, Hedd A, Taylor PD, Montevecchi WA, Shutler D. Migratory movements and wintering areas of 
Leachs StormPetrels tracked using geolocators. Journal of Field Ornithology. 2014;85:321-328.

42. Lisovski S, Wotherspoon S, Sumner M. TwGeos: Basic data processing for light-level geolocation archival tags $\mathrm{R}$ package; 2016. $\mathrm{R}$ package version 0.1.2.

43. Lisovski S, Bauer S, Briedis M, Davidson SC, Dhanjal-Adams KL, Hallworth MT, et al. Light-level geolocator analyses: A user's guide. Journal of Animal Ecology. 2019;89:221-236.

44. Wotherspoon SJ, Sumner MD, Lisovski S. SGAT: Solar/Satellite geolocation for animal tracking R package; 2016. R package version 0.1.3.

45. Wilson RP, Culik BM, Kosiorek P, Adelung D. Estimation of location: global coverage using light intensity. In: Priede IM, Swift SM, editors. Wildlife telemetry: remote monitoring and tracking of animals. Chichester: Ellis Horward; 1992. p. 131-134.

46. Hill RD. Theory of Geolocation by Light Levels. In: Le Boeuf BJ, Laws RM, editors. Elephant seals: population ecology, and physiology. Berkeley, USA: University of California Press; 1994. p. 227-236.

47. Bertrand A, Gerlotto F, Bertrand S, Gutiérrez M, Alza L, Chipollini A, et al. Schooling behaviour and environmental forcing in relation to anchoveta distribution: An analysis across multiple spatial scales. Progress in Oceanography. 2008;79:264-277.

48. Cazelles B, Chavez M, Berteaux D, Ménard F, Vik JO, Jenouvrier S, et al. Wavelet analysis of ecological time series. Oecologia. 2008;156:287-304.

49. Fablet R, Chaigneau A, Bertrand S. Multiscale analysis of geometric planar deformations: application to wild animal electronic tracking and satellite ocean observation data. IEEE Transactions on Geoscience and Remote Sensing. 2013;52:3627-3636.

50. Jenouvrier S, Weimerskirch H, Barbraud C, Park YH, Cazelles B. Evidence of a shift in the cyclicity of Antarctic seabird dynamics linked to climate. Proceedings of the Royal Society B: Biological Sciences. 2005;272:887-895.

51. Cazelles B, Stone L. Detection of imperfect population synchrony in an uncertain world. Journal of Animal Ecology. 2003;72:231-242.

52. Torrence C, Compo GP. A practical guide to wavelet analysis. Bulletin of the American Meteorological society. 1998;79:61-78.

53. Cazelles B, Cazelles K, Chavez M. Wavelet analysis in ecology and epidemiology: impact of statistical tests. Journal of the Royal Society Interface. 2014;11:20130585.

54. Rouyer T, Fromentin JM, Stenseth NC, Cazelles B. Analysing multiple time series and extending significance testing in wavelet analysis. Marine Ecology Progress Series. 2008;359:11-23.

55. Rosch A, Schmidbauer H. WaveletComp R package; 2018. R package version 1.1.

56. Bächler E, Hahn S, Schaub M, Arlettaz R, Jenni L, Fox JW, et al. Year-Round Tracking of Small Trans-Saharan Migrants Using Light-Level Geolocators. PLoS ONE. 2010;5:e9566.

57. Stenhouse IJ, Egevang C, Phillips RA. Trans-equatorial migration, staging sites and wintering area of Sabine's Gulls Larus sabini in the Atlantic Ocean: Sabine's Gull migration. Ibis. 2012;154:42-51.

58. Leal GR, Furness RW, McGill RAR, Santos RA, Bugoni L. Feeding and foraging ecology of Trindade petrels Pterodroma arminjoniana during the breeding period in the South Atlantic Ocean. Marine Biology. 2017;164(11):211.

59. Guilford T, Meade J, Willis J, Phillips RA, Boyle D, Roberts S, et al. Migration and stopover in a small pelagic seabird, the Manx shearwater Puffinus puffinus : insights from machine learning. Proceedings of the Royal Society B: Biological Sciences. 2009;276:1215-1223.

60. Kepler CB. The breeding biology of the blue-faced booby (Sula dactylatra personata) on Green Island, Kure atoll. Publications of the Nuttall Ornithologists Club. 1969;8.

61. Woodward PW. The natural history of Kure Atoll, northwestern Hawaiian islands. Atoll Research Bulletin. 1972;164.

62. de Santana Campelo RP, Bonou FK, de Melo Júnior M, Diaz XFG, Bezerra LEA, Neumann-Leitão S. Zooplankton biomass around marine protected islands in the tropical Atlantic Ocean. Journal of Sea Research. 2019;154:101810.

63. Antas PTZ. Status and conservation of seabirds breeding in Brazilian waters. ICBP Technical Publication. 1991;11:141-158.

64. Sazima I, de Almeida LB. The bird kraken: octopus preys on a sea bird at an oceanic island in the tropical West Atlantic. Marine Biodiversity Records. 2008;1:e47.

65. Mancini PL, Bond AL, Hobson KA, Duarte LS, Bugoni L. Foraging segregation in tropical and polar seabirds: Testing the Intersexual Competition Hypothesis. Journal of experimental marine biology and ecology. 2013;449:186-193.

66. Mancini PL, Hobson KA, Bugoni L. Role of body size in shaping the trophic structure of tropical seabird communities. Marine Ecology Progress Series. 2014;497:243-257.

67. Serrano-Meneses MA, Székely T. Sexual size dimorphism in seabirds: sexual selection, fecundity selection and differential niche-utilisation. Oikos. 2006;113:385-394.

68. Lisovski S, Schmaljohann H, Bridge ES, Bauer S, Farnsworth A, Gauthreaux SA, et al. Inherent limits of light-level geolocation may lead to over-interpretation. Current Biology. 2018;28:R99-R100.

Figures

Additional Files

Scripts and additional results are on a GitHub repository: https://github.com/AmedeeRoy/WaveLightGLS. 
Figure 1 Histograms of twilight times and temperature deviation from Fernando de Noronha Grey histograms consider the calibration period only (2017-05-10 to 2017-06-15). Blue histograms consider all deployment period (2017-05-05 to 2018-04-23). Orange histograms consider periods where the mean saltwater immersion time is above $75 \%$. Red-dotted curves correspond to the error structure used in Figure 2.

Figure 2 Geolocation error and habitat maps

Maps of geolocation error (red) correspond to the geographical error range estimation of a GLS fixed at Fernando de Noronha, Brazil, based on the error structure presented in Figure 1. Map of habitat (blue) have been estimated using observed data from all geolocator. Map of wet habitat (orange) are a subset of the habitat maps where coordinates that have been used correspond to period between two consecutive twilights where the mean saltwater immersion time is above $75 \%$. In (a) all coordinates have been used, in

(b) we used coordinates weighted by their likelihood (based on temperature data). EEZ - Exclusive Economic Zone

Figure 3 Cross-wavelet power coefficient matrix

The upper plot is an extract of longitude and activity (i.e. daily wet time) time-series derived from a geolocator. The bottom plot is the respective cross-wavelet power coefficient matrix. White lines contour the time/period pairs with significant synchronicity $(p<0.01)$. White arrows illustrate the difference of phases between the two time-series (derived from wavelet analysis). More precisely, horizontal arrows pointing to the right indicate that the two series are in phase at the respective period (more details in [55]). The two plots on the right (a) and (b), consist in two distinct windows in the time-series. Red lines show the Morlet wavelet used for the analysis for the two time/period pairs illustrated by red crosses on the coefficient matrix. Grey rectangles show nights.

Figure 4 Sex-specific averaged cross-wavelet power coefficient matrixes

Averaged cross-wavelet power coefficient matrixes of longitude and activity time-series based on the analysis of all geolocators over the whole deployment for separately female $(n=14)$ and male $(n=17)$.

White lines contour the time/period pairs where at least one individual have shown significant joint-periodicity between the two time-series. White arrows illustrate the difference of phases between the two time-series (see Figure 3 for further explanations). The white area corresponds to the cone of influence (see [48]). The plot below shows approximately the different stages of the phenology of masked boobies at Fernando de Noronha, Brazil, based on in situ observations. (a), (b) and (c) show the averaged power over the three respective time-windows. ( $c$ ') show the eastward deviation from Fernando de Noronha of position estimated over the time-window (c) associated with highly wet environments $(75 \%)$. Individual analysis are available on a GitHub repository (AmedeeRoy/WaveLightGLS). 
Figures
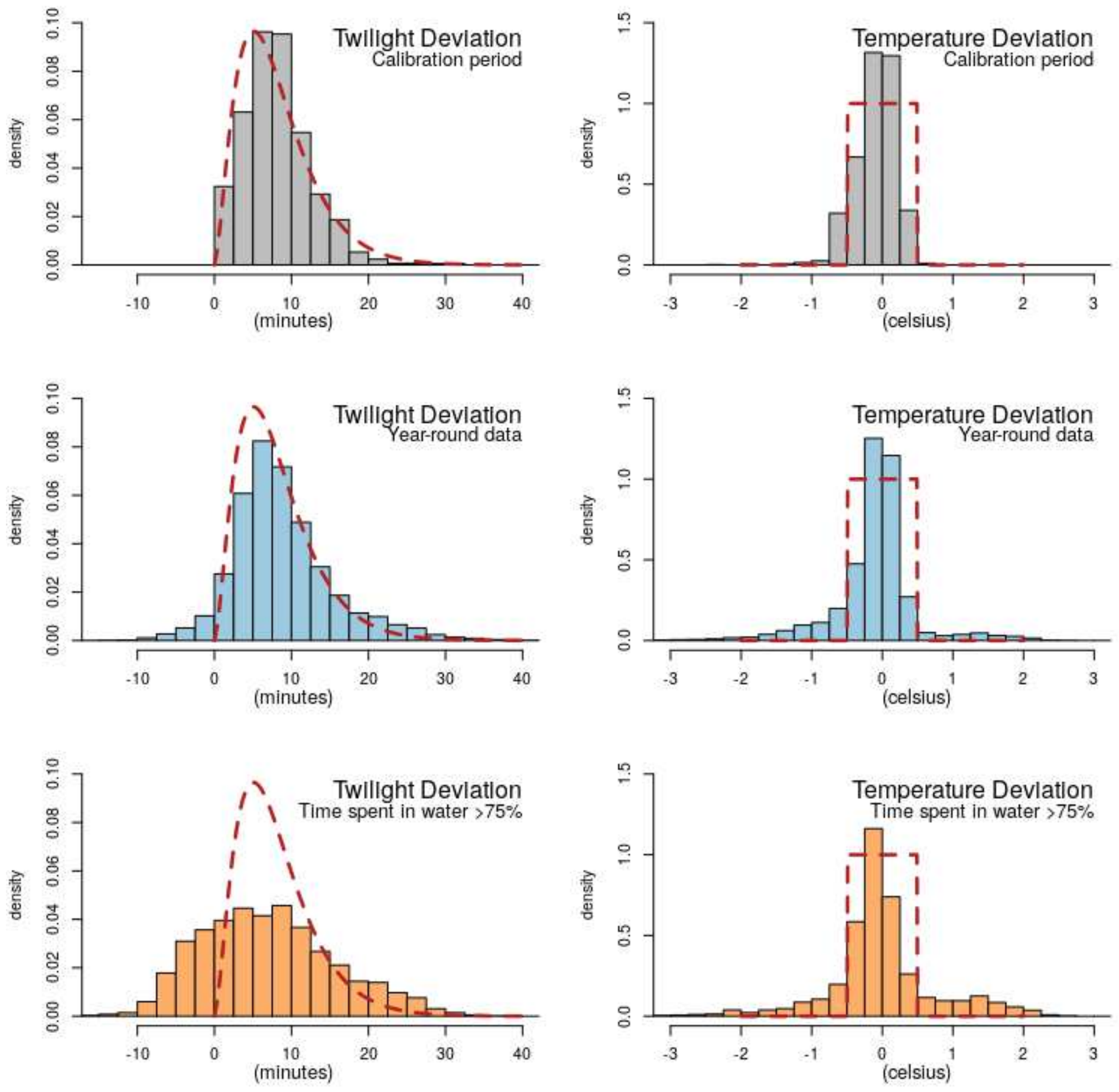

Figure 1

Histograms of twilight times and temperature deviation from Fernando de Noronha Grey histograms consider the calibration period only (2017-05-10 to 2017-06-15). Blue histograms consider all deployment period (2017-05-05 to 2018-04-23). Orange histograms consider periods where the mean saltwater immersion time is above $75 \%$. Red-dotted curves correspond to the error structure used in Figure 2. 
(a) Error Range Estımation Presence in EEZ : $84 \%$

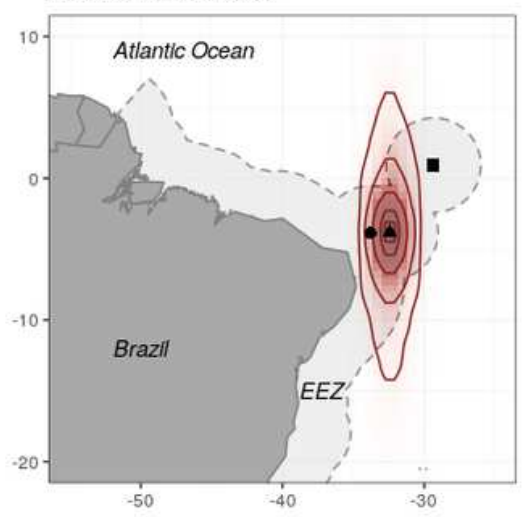

(b) Error Range Estimation Presence in EEZ : $95 \%$

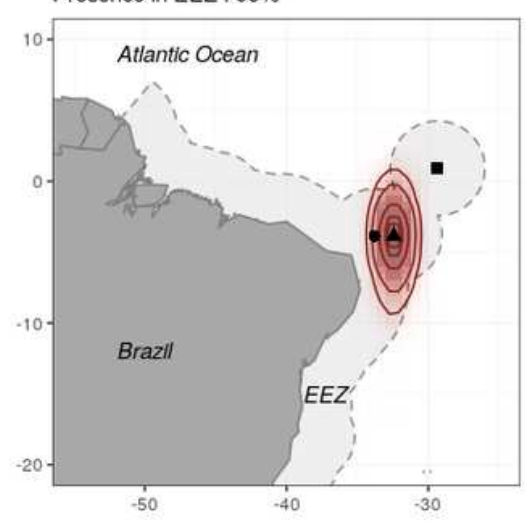

(a) Habitat Estimation Presence in EEZ : $77 \%$

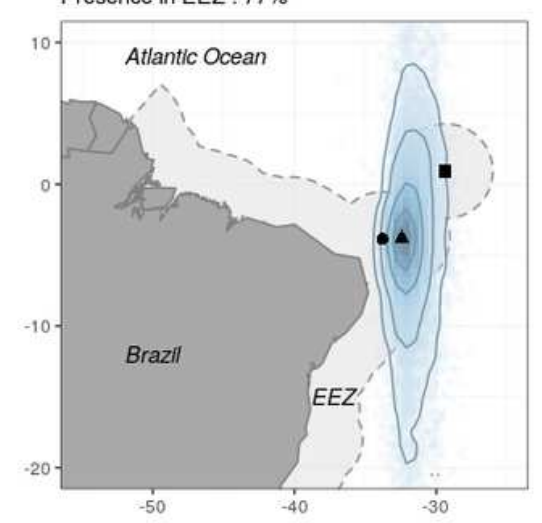

(b) Habltat Estlmation Presence in EEZ : $93 \%$

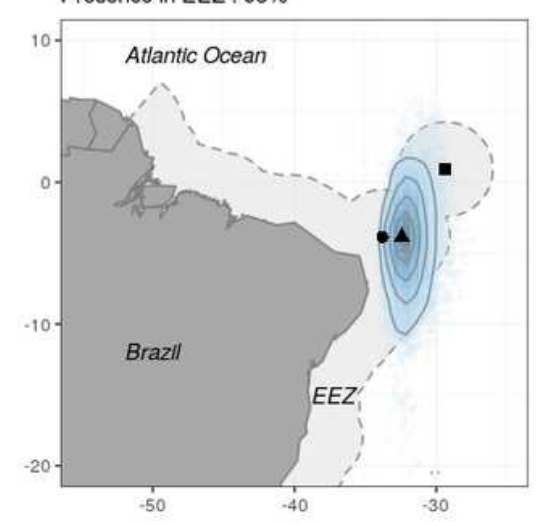

(a) Wet Habltat Estlmation Presence in EEZ : $67 \%$

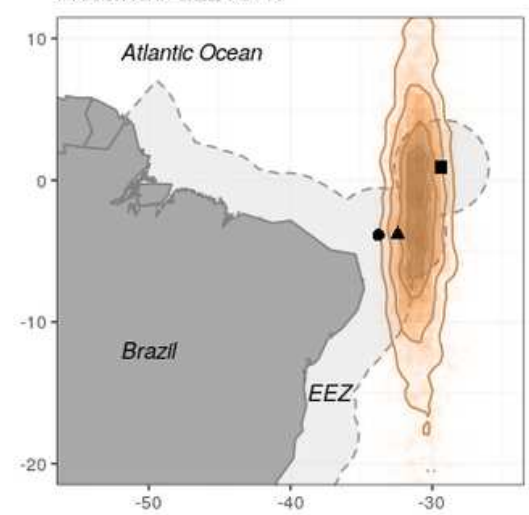

(b) Wet Habltat Estımation Presence in EEZ : $85 \%$

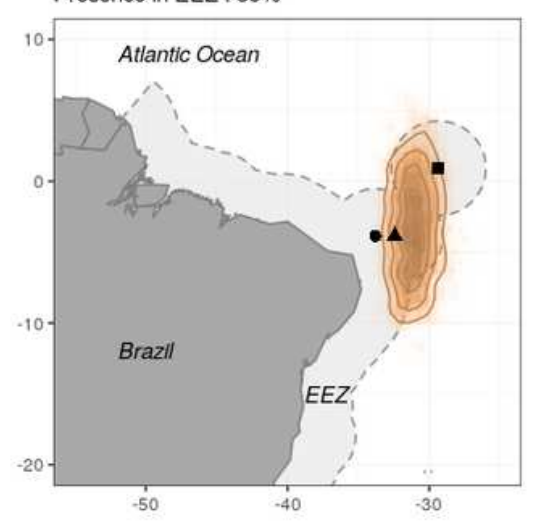

\section{Figure 2}

Geolocation error and habitat maps. Maps of geolocation error (red) correspond to the geographical error range estimation of a GLS fixed at Fernando de Noronha, Brazil, based on the error structure presented in Figure 1. Map of habitat (blue) have been estimated using observed data from all geolocator. Map of wet habitat (orange) are a subset of the habitat maps where coordinates that have been used correspond to period between two consecutive twilights where the mean saltwater immersion time is above $75 \%$. In (a) all coordinates have been used, in (b) we used coordinates weighted by their likelihood (based on temperature data). EEZ Exclusive Economic Zone 

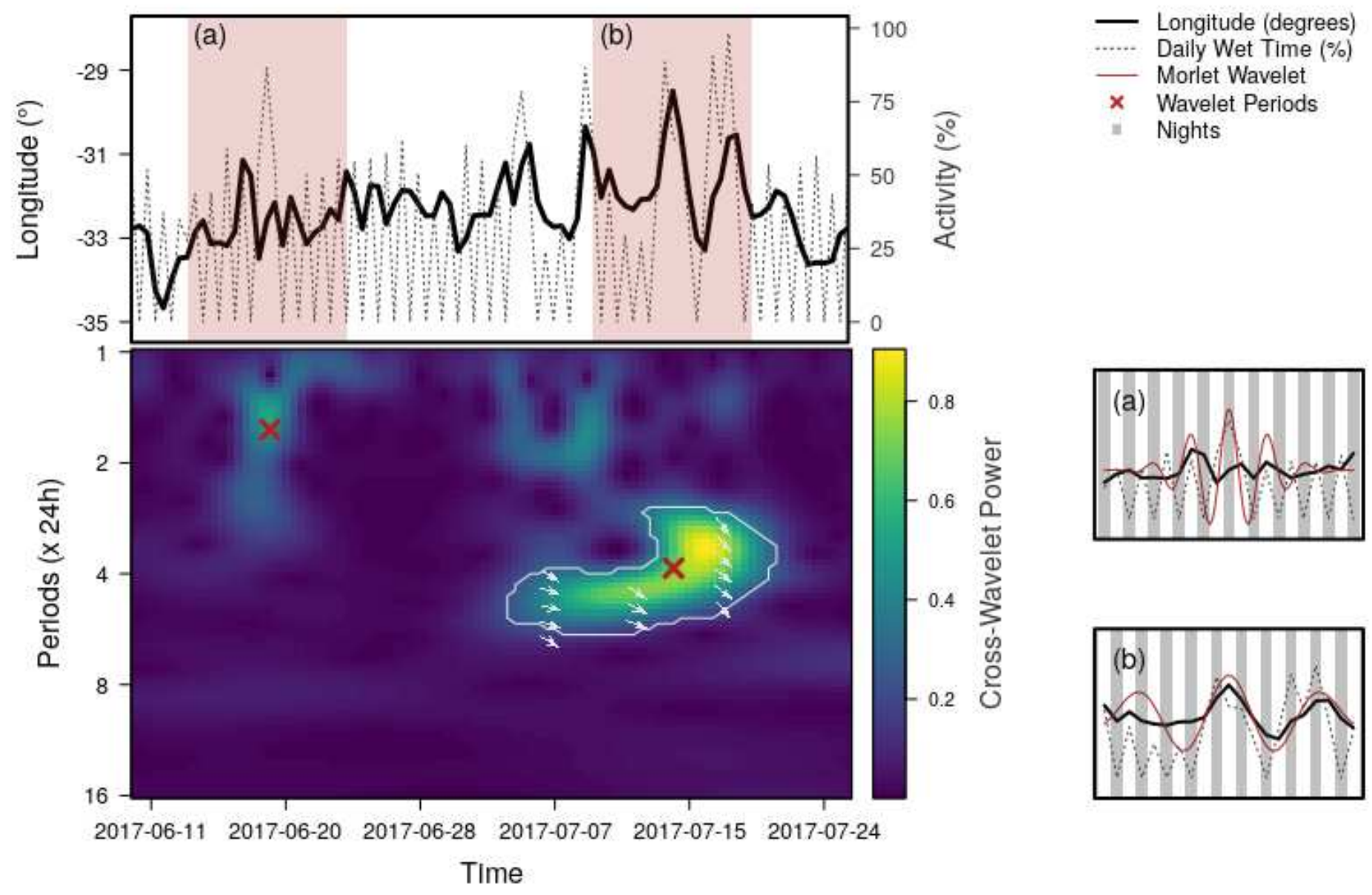

\section{Figure 3}

Cross-wavelet power coefficient matrix The upper plot is an extract of longitude and activity (i.e. daily wet time) time-series derived from a geolocator. The bottom plot is the respective cross-wavelet power coefficient matrix. White lines contour the time/period pairs with significant synchronicity $(p<0.01)$. White arrows illustrate the difference of phases between the two time-series (derived from wavelet analysis). More precisely, horizontal arrows pointing to the right indicate that the two series are in phase at the respective period (more details in [55]). The two plots on the right (a) and (b), consist in two distinct windows in the time-series. Red lines show the Morlet wavelet used for the analysis for the two time/period pairs illustrated by red crosses on the coefficient matrix. Grey rectangles show nights. 

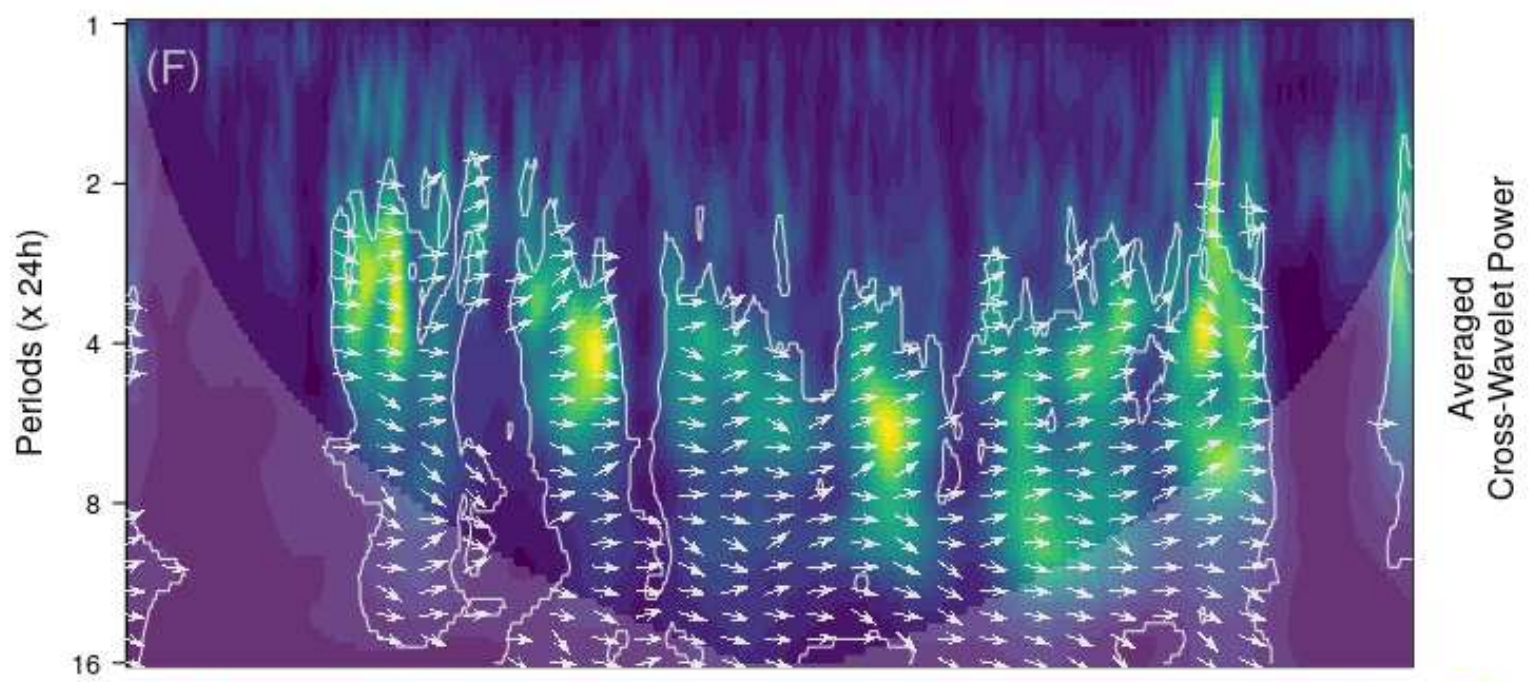

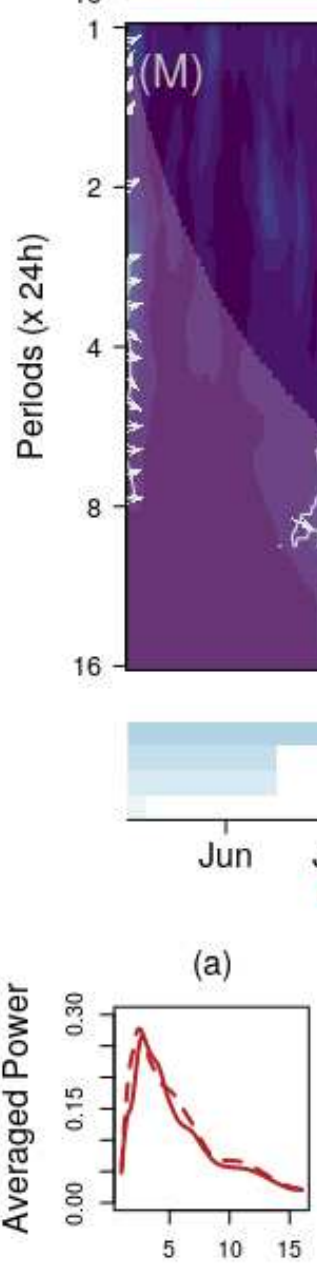

Perlods

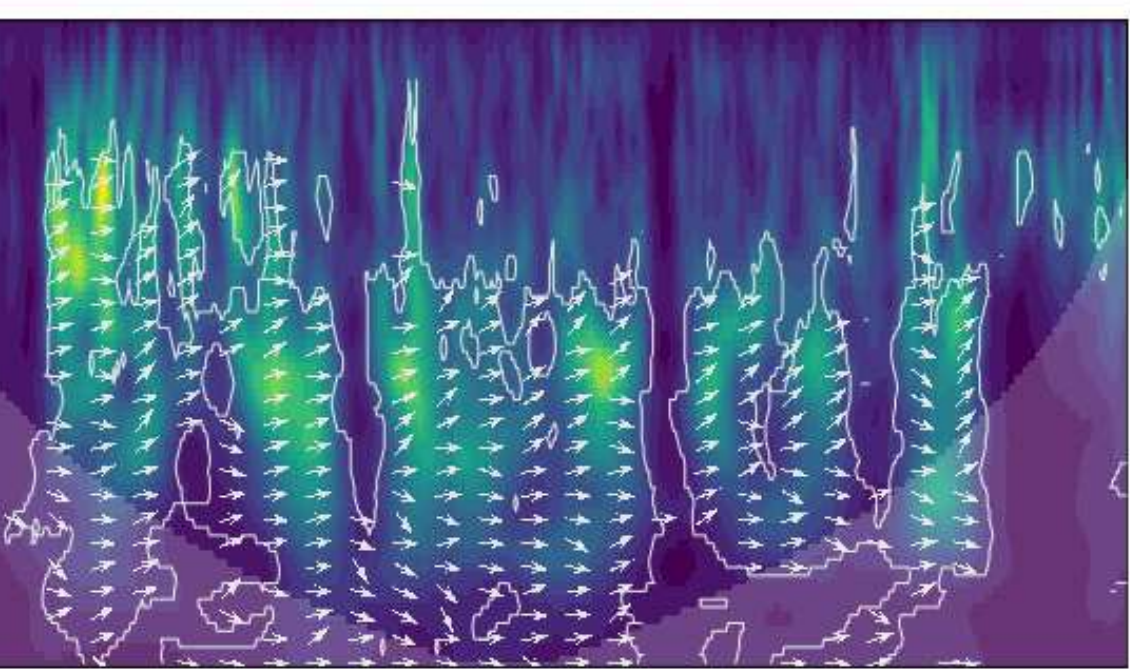

1
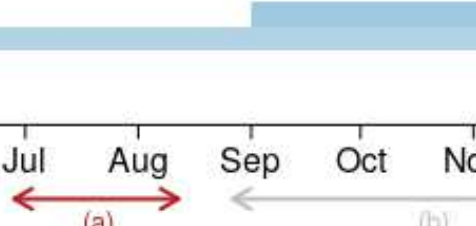

(a)

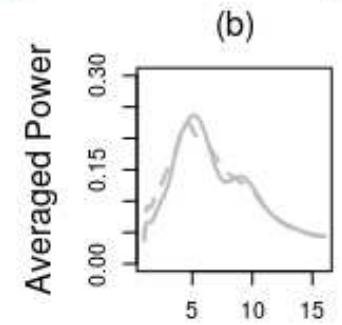

Perlods

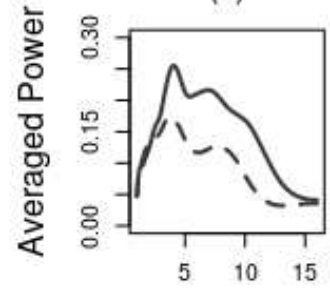

Perlods

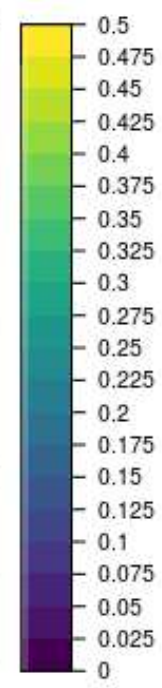

fledging rearing incubating laying

(c')

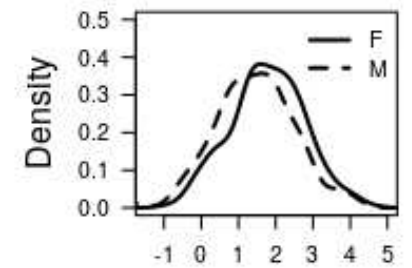

Eastward Devlation (degrees)

\section{Figure 4}

Sex-specific averaged cross-wavelet power coefficient matrixes Averaged cross-wavelet power coefficient matrixes of longitude and activity time-series based on the analysis of all geolocators over the whole deployment for separately female $(n=14)$ and male $(n=17)$. White lines contour the time/period pairs where at least one individual have shown significant joint-periodicity between the two time-series. White arrows illustrate the difference of phases between the two time-series (see Figure 3 for further 
explanations). The white area corresponds to the cone of influence (see [48]). The plot below shows approximately the different stages of the phenology of masked boobies at Fernando de Noronha, Brazil, based on in situ observations. (a), (b) and (c) show the averaged power over the three respective timewindows. (c') show the eastward deviation from Fernando de Noronha of position estimated over the time-window (c) associated with highly wet environments (75\%). Individual analysis are available on a GitHub repository (AmedeeRoy/WaveLightGLS). 